\title{
Prediction of general practice workload from census based social deprivation scores
}

\author{
Yoav Ben-Shlomo, Ian White, Paul M McKeigue
}

\begin{abstract}
Study objective-The aim was to compare the ability of census based social deprivation scores devised by Jarman, Carstairs, and Townsend to predict workload in general practice.

Design-This was a prospective study of 140050 patients registered with general practices over one year from 1 July 1981 (Third National Morbidity Survey). Main outcome measures were workload score for each patient, defined as a weighted sum of consultations at the surgery and consultations elsewhere, excluding preventive procedures.
\end{abstract}

Setting-25 general practices in England and Wales.

Main results-In multivariate analyses the Jarman, Carstairs, and Townsend indices all predicted workload, but the Townsend index was the best predictor, with both housing tenure and car ownership being strong predictors of workload. The overcrowding and geographical mobility variables used in the Jarman index did not predict increased workload. The weighting assigned to children under five by the Jarman index underestimated the additional workload this group generated.

Conclusions-For identifying social pressures on general practice workload the Jarman index is less valid than other census based scores because it fails to include car ownership and housing tenure. A more rational scheme for compensating general practitioners would directly weight the capitation fee for children aged under five years and allocate current deprivation payments according to the Townsend index or a similar score. This would redistribute resources from London to deprived areas in northern England.

f Epidemiol Community Health 1992; 46: 532-536

Reports in the early 1980 s on the problems of primary health care in inner cities emphasised the need for some means of identifying deprived areas where general practitioners faced greater difficulties. ${ }^{12}$ A census based score was devised for this purpose by Jarman. ${ }^{3}$ Initial selection of variables was based on the opinions of general practitioners in London and weightings for a final score based on eight census variables were derived from a subsequent national survey of general practitioners. To validate the index, area scores were compared with the opinions of family practitioner committees and general practitioners. ${ }^{4}$
Associations were demonstrated with adverse health outcomes, ${ }^{5}$ admission rates, ${ }^{67}$ permanent sickness, ${ }^{6}$ and self reported ill health. ${ }^{8}$

It was subsequently "thought desirable to give extra support" to areas with high Jarman scores ${ }^{3}$ and on this basis some $£ 25$ million of capitation fees were redistributed in 1990-91. ${ }^{9}$ The use of this index has however also generated criticism. $^{10-12}$. Other census based deprivation scores have been developed by Townsend ${ }^{13}$ and Carstairs. ${ }^{14}$ All three scores correlate with each other ${ }^{15}$ and with indicators of ill health, ${ }^{6}{ }^{16}$ but the Townsend and Carstairs indices identify more deprived areas in the north of the United Kingdom than the Jarman index. ${ }^{17}$ We have used data from the 1981 third national morbidity survey ${ }^{18}$ in an attempt to validate the Jarman index for its initial purpose, that of identifying practices with greater pressure of workload. We also compared the Jarman, Townsend, and Carstairs indices to determine which of the currently existing indices is the best to use if general practitioners are to be remunerated for extra workload associated with social factors.

\section{Methods}

\section{MORBIDITY SURVEY}

In the third national survey, 48 practices around the country recorded all consultations for one year from 1 July 1981 using a standardised episode book (for detailed description of methods see ${ }^{18}$ ), and 140050 individuals registered with 25 practices were matched to their 1981 census records. Each consultation was classified as a surgery visit, home visit, or visit elswhere. Consultations for morbidity were classified separately from consultations for preventive care such as vaccinations or family planning.

DEFINITION OF OUTCOME AND EXPLANATORY VARIABLES

Workload score for each individual was defined as the number of surgery visits plus 2.5 times the number of consultations at home or elsewhere, excluding consultations for preventive procedures. This takes into account that home visits are more time consuming than surgery consultations and is based on an estimate of general practice workload. ${ }^{19}$ Some analyses were repeated using a weight of 3 to check the sensitivity of the assumption. As most preventive procedures are remunerated directly anyway, these were excluded from the workload score.

Each deprivation score uses different variables, though some variables are common to several indices (table I). Rates are based on households in the Townsend index but on all residents in the 
Table I Variables used in the farman, Carstairs, and Townsend models

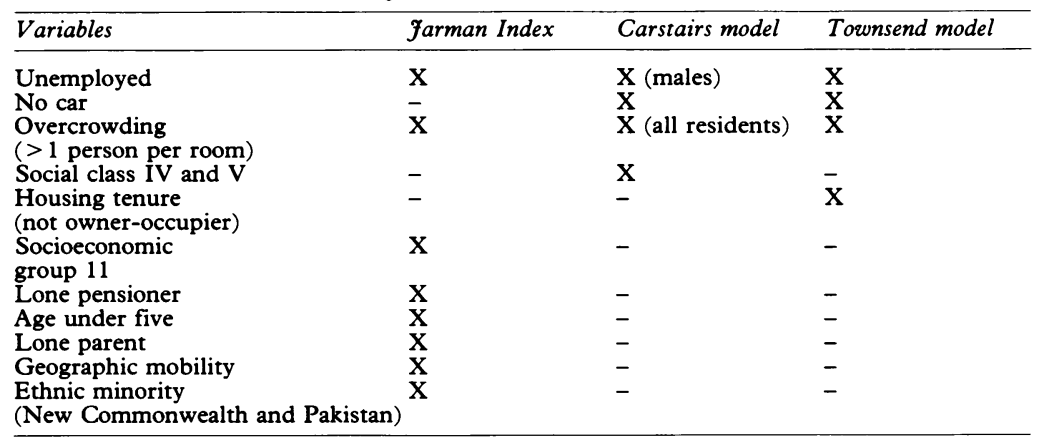

Carstairs and Jarman indices. In this analysis the definition of each variable refers to individuals or their household coded as a dichotomous variable (yes/no), rather than to the proportion in an area as in the original deprivation scores. For example for a child, the car ownership variable is coded "yes" if that child lives in a household with access to a car. The "lone parent" variable applies to both parent and children. Social class was defined according to the Registrar General's criteria. The "unskilled" variable used in the Jarman index is defined by households headed by a person in socioeconomic group II; this was not available in the national morbidity survey so social class $V$ was used as a close equivalent. ${ }^{20}$ Married or cohabiting women were coded according to their partners' social class and employment status, while other women were classified by own social class. The "unemployment" variable has three levels: employed, unemployed, and inapplicable (permanently sick, out of working age, housewife, or student). This was represented in the model by two indicator variables for the unemployed and inapplicable categories, with the employed category as baseline; coefficients presented are for unemployed relative to employed.

\section{STATISTICAL ANALYSIS}

Odds ratios

Associations between census variables were examined by calculating odds ratios for $2 \times 2$ tables except for combinations which were mutually exclusive. These odds ratios are shown in table II; ratios greater than 1 indicate positive associations.
Model form

Prediction of workload score from census variables was examined by least squares regression analyses. Before analysing such a highly skewed variable it is more usual to transform it or allow for heterogeneity of variance. For our analysis a transformation was undesirable since we wanted to produce a linear predictor for individuals which would also be valid for predicting the mean workload generated by groups. Allowance for heterogeneity of variance would weight frequent consulters less than occasional consulters, whereas it is more meaningful to weight all consultations equally. When least squares regression is used with highly skewed data in small or medium sized datasets the standard errors may be innaccurate but this is not likely to be a serious problem in a dataset of this size. As a safeguard, we adopted a validation sample approach (see below).

\section{Model analyses}

Practice, "age over 65", and "age over 75" were included as categoric variables in all regression models. We controlled for practice in order to examine differences between individuals within practices rather than differences between practices. Age over 65 and age over 75 are already remunerated by additional capitation fees and our objective was to predict effects additional to these factors. The "over 65" variable was dropped from the Jarman index for the same reason. ${ }^{3}$ We did not stratify further by age bands as we did not intend to determine the workload associated with each age group but rather to validate the currently existing indices.

Prediction of workload by each variable was first examined in a univariate model. To compare the deprivation scores proposed by Jarman, Townsend, and Carstairs, a model was constructed for each index containing the appropriate choice of variables and the multivariate regression coefficients were estimated. For the set of variables used in the Jarman index, prediction of workload based on the weightings chosen by multivariate regression was compared with prediction based on the weightings derived by Jarman from a survey of general practitioners. For this purpose a score was calculated for each individual as a weighted sum of the variables using the weightings chosen by Jarman; this score

Table II Odds ratios for associations between variables used in farman, Townsend, and Carstairs models (95 ${ }^{\circ}$ confidence interval)

\begin{tabular}{|c|c|c|c|c|c|c|c|c|c|c|c|}
\hline & $\begin{array}{l}\text { Lone } \\
\text { pensioner }\end{array}$ & Under 5 & $\begin{array}{l}\text { Lone } \\
\text { parent }\end{array}$ & Unskilled & Unemployed & Crowded & $\begin{array}{l}\text { Changed } \\
\text { adress }\end{array}$ & $\begin{array}{l}\text { Ethnic } \\
\text { minority }\end{array}$ & No car & Tenure & $\begin{array}{l}\text { Class } \\
4 \text { and } 5\end{array}$ \\
\hline $\begin{array}{l}\text { Lone pensioner } \\
\text { Under } 5\end{array}$ & $\overline{\text { me }}$ & - & & & & & & & & & \\
\hline Lone parent & me & $\begin{array}{l}2.03 \\
(1 \cdot 82-2 \cdot 26)\end{array}$ & - & & & & & & & & \\
\hline Unskilled & $\begin{array}{l}0.91 \\
(0.80-1.03)\end{array}$ & $\begin{array}{l}1.07 \\
(0.96-1 \cdot 19)\end{array}$ & $\begin{array}{l}1 \cdot 15 \\
(0.96-1.37)\end{array}$ & - & & & & & & & \\
\hline Unemployed & me & me & $\begin{array}{l}2 \cdot 83 \\
(2 \cdot 52-3 \cdot 18)\end{array}$ & me & - & & & & & & \\
\hline Crowded & me & $\begin{array}{l}2 \cdot 19 \\
(2 \cdot 05-2 \cdot 33)\end{array}$ & $\begin{array}{l}0.55 \\
(0.45-0.67)\end{array}$ & $\begin{array}{l}2 \cdot 23 \\
(2 \cdot 05-2 \cdot 43)\end{array}$ & $\begin{array}{l}2 \cdot 07 \\
(1 \cdot 95-2 \cdot 19)\end{array}$ & - & & & & & \\
\hline Changed address & $\begin{array}{l}s 0.34 \\
(0.30-0.38)\end{array}$ & $\begin{array}{l}2 \cdot 05 \\
(1 \cdot 92-2 \cdot 20)\end{array}$ & $\begin{array}{l}1 \cdot 90 \\
(1 \cdot 73-2 \cdot 10)\end{array}$ & $\begin{array}{l}0.85 \\
(0.77-0.94)\end{array}$ & $\begin{array}{l}1.35 \\
(1 \cdot 29-1 \cdot 41)\end{array}$ & $\begin{array}{l}1 \cdot 11 \\
(1 \cdot 03-1 \cdot 19)\end{array}$ & - & & & & \\
\hline Ethnic minority & $\begin{array}{l}0 \cdot 10 \\
(0 \cdot 08-0 \cdot 13)\end{array}$ & $\begin{array}{l}2.09 \\
(1.94-2 \cdot 25)\end{array}$ & $\begin{array}{l}2 \cdot 68 \\
(2 \cdot 40-3 \cdot 00)\end{array}$ & $\begin{array}{l}1 \cdot 18 \\
(1.04-1 \cdot 33)\end{array}$ & $\begin{array}{l}1.75 \\
(1.64-1 \cdot 86)\end{array}$ & $\begin{array}{l}7 \cdot 42 \\
(7 \cdot 05-7 \cdot 81)\end{array}$ & $\begin{array}{l}1 \cdot 60 \\
(1 \cdot 49-1 \cdot 72)\end{array}$ & - & & & \\
\hline No car & $\begin{array}{l}15 \cdot 9 \\
(15 \cdot 1-16 \cdot 7)\end{array}$ & $\begin{array}{l}0.98 \\
(0.94-1.03)\end{array}$ & $\begin{array}{l}6 \cdot 67 \\
(6 \cdot 21-7 \cdot 16)\end{array}$ & $\begin{array}{l}3.46 \\
(3 \cdot 27-3 \cdot 65)\end{array}$ & $\begin{array}{l}1.82 \\
(1.76-1 \cdot 88)\end{array}$ & $\begin{array}{l}1 \cdot 70 \\
(1 \cdot 62-1 \cdot 78)\end{array}$ & $\begin{array}{l}1.17 \\
(1 \cdot 13-1 \cdot 22)\end{array}$ & $\begin{array}{l}1.73 \\
(1.64-1.81)\end{array}$ & - & & \\
\hline Tenure & $\begin{array}{l}2 \cdot 12 \\
(2 \cdot 02-2 \cdot 22)\end{array}$ & $\begin{array}{l}1 \cdot 12 \\
(1 \cdot 07-1 \cdot 16)\end{array}$ & $\begin{array}{l}3.94 \\
(3.65-4.22)\end{array}$ & $\begin{array}{l}3 \cdot 29 \\
(3 \cdot 11-3 \cdot 48)\end{array}$ & $\begin{array}{l}1.47 \\
(1.43-1 \cdot 52)\end{array}$ & $\begin{array}{l}2 \cdot 54 \\
(2 \cdot 43-2 \cdot 65)\end{array}$ & $\begin{array}{l}1.90 \\
(1.83-1.97)\end{array}$ & $\begin{array}{l}0.78 \\
(0.74-0.83)\end{array}$ & $\begin{array}{l}4 \cdot 63 \\
(4 \cdot 52-4 \cdot 74)\end{array}$ & - & \\
\hline Class 4 and 5 & $\begin{array}{l}0.70 \\
(0.65-0.75)\end{array}$ & $\begin{array}{l}0.93 \\
(0.88-0.98)\end{array}$ & $\begin{array}{l}1.00 \\
(0.90-1 \cdot 10)\end{array}$ & $\infty$ & me & $\begin{array}{l}1.89 \\
(1.80-1.99)\end{array}$ & $\begin{array}{l}0.88 \\
(0.84-0.93)\end{array}$ & $\begin{array}{l}1 \cdot 41 \\
(1 \cdot 33-1 \cdot 50)\end{array}$ & $\begin{array}{l}2 \cdot 45 \\
(2 \cdot 38-2 \cdot 53)\end{array}$ & $\begin{array}{l}2 \cdot 65 \\
(2 \cdot 57-2 \cdot 72)\end{array}$ & - \\
\hline
\end{tabular}

me $=$ mutually exclusive 
Table III Univariate coefficients for variables in the farman, Townsend, and Carstairs models ${ }^{\mathrm{a}}$

\begin{tabular}{|c|c|c|c|}
\hline & No of observations & $\begin{array}{l}\text { Extra workload } \\
\text { (standard error) }\end{array}$ & $p$ value \\
\hline $\begin{array}{l}\text { Lone pensioner } \\
\text { Under } 5 \\
\text { Social class V (unskilled) } \\
\text { Unemployed } \\
\text { Lone parent } \\
\text { Overcrowding } \\
\text { Change of address } \\
\text { Ethnic minorities }\end{array}$ & $\begin{array}{l}139049 \\
140049 \\
136979 \\
138232 \\
140049 \\
138232 \\
136412 \\
140049\end{array}$ & $\begin{array}{c}\text { used in .7arman in } \\
0.728(0.091) \\
1.004(0.070) \\
0.583(0.095) \\
0.545(0.049) \\
0.288(0.123) \\
-0.234(0.074) \\
0.000(0.062) \\
0.248(0.089)\end{array}$ & $\begin{array}{l}x \\
0.0001 \\
0.0001 \\
0.0001 \\
0.0001 \\
0.020 \\
0.0015 \\
\text { NS } \\
0.0054\end{array}$ \\
\hline $\begin{array}{l}\text { No car } \\
\text { Not owner-occupier }\end{array}$ & $\begin{array}{l}\text { Additional var } \\
140049 \\
138300\end{array}$ & $\begin{array}{c}\text { bles used in Towns } \\
0.848(0.042) \\
0.574(0.038)\end{array}$ & $\begin{array}{r}d \text { model } \\
0.0001 \\
0.0001\end{array}$ \\
\hline Social Class 4 and 5 & \multicolumn{3}{|c|}{$\begin{array}{l}\text { Additional variables used in Carstairs model } \\
140049 \\
0.427(0.049)\end{array}$} \\
\hline
\end{tabular}

${ }^{a}$ Each analysis includes age over $65 / 75$, practice, and the variable of interest.

was included in a regression model as a single continuous variable. This is referred to as the Jarman "score" index. A "derived" index, containing the best possible subset of all variables suggested by Jarman, Townsend, and Carstairs, was selected by minimising Mallow's $C_{p}$ coefficient on the first half of the dataset. ${ }^{21}$

\section{Validation}

To test the predictive power of each index, the sample was randomly divided into two halves. All coefficients were derived from the first half of the dataset and then applied to the second half (the validation sample) to assess the prediction error for each individual. Individuals with missing data on any variable were excluded, so that all models had the same number of observations.

To test whether differences in predictive ability between two models might be due to chance, a "competing models" approach was used. In this it is assumed that workload score is best predicted by a weighted average of the two predictors:

Table IV Ranking and relative weighting of farman variables according to farman index and multivariate model

\begin{tabular}{|c|c|c|c|c|}
\hline & \multicolumn{2}{|c|}{ tarman index } & \multicolumn{2}{|c|}{ Multivariate model } \\
\hline & Ranking & Relative weights & Ranking & Relative weights \\
\hline $\begin{array}{l}\text { Lone pensioner } \\
\text { Under fives } \\
\text { Social class V } \\
\text { Unemployed } \\
\text { Lone parent } \\
\text { Overcrowding } \\
\text { Change of address } \\
\text { Ethnic minority }\end{array}$ & $\begin{array}{l}1 \\
2 \\
3 \\
4 \\
5 \\
6 \\
7 \\
8\end{array}$ & $\begin{array}{l}2.6 \\
1.9 \\
1.5 \\
1.3 \\
1.2 \\
1.2 \\
1.1 \\
1.0\end{array}$ & $\begin{array}{l}2 \\
1 \\
4 \\
3 \\
5 \\
8^{\mathrm{a}} \\
7^{\mathrm{a}} \\
6\end{array}$ & $\begin{array}{l}2 \cdot 3 \\
5 \cdot 3 \\
2 \cdot 2 \\
2 \cdot 3 \\
1 \cdot 8 \\
\overline{-} \\
\overline{1} \cdot 0\end{array}$ \\
\hline
\end{tabular}

${ }^{a}$ Associated with fewer consultations rather than more

Table $V$ Predictive ability of models based on coefficients generated from a random half of the sample $(n=65492)$ and applied to the validation half $(n=65541)$

\begin{tabular}{llll}
\hline Models & $\begin{array}{l}\text { Percent variance } \\
\text { explained }\end{array}$ & $\begin{array}{l}\text { Ratio of additional } \\
\text { variance relative } \\
\text { to model }(2)^{\mathrm{a}}\end{array}$ & p value \\
\hline $\begin{array}{l}\text { (1) Over 65/over } 75 \text { and practice } \\
\text { Basic model: }\end{array}$ & 8.65 & 0 & - \\
$\begin{array}{l}\text { (2) Jarman model (data weighted) } \\
\text { Comparison models: }\end{array}$ & 9.02 & 1.00 & - \\
$\begin{array}{l}\text { (3) Jarman model (score) } \\
\text { (4) Carstairs model }\end{array}$ & 8.81 & 0.44 & $<0.001$ \\
(5) Townsend model & 9.08 & 1.11 & 0.09 \\
(6) Derived model & 9.14 & 1.28 & 0.008 \\
\end{tabular}

${ }^{a}$ This column is derived by dividing the additional variance for models $3-6$ over model 1 by the additional variance for model 2 over model 1.

${ }^{b}$ The derived model contains the following variables: car ownership, age under five, unem-

The derived model contains the following variables: car ownership, age under five, unem
ployment, housing tenure, social class IV or V, overcrowding, lone pensioner, and ethnic minority.
Workload score $=\tau \times$ predictor 1
$+(1-\tau) \times$ predictor $2+$ error

A linear regression of (workload score minus predictor 2) on (predictor 1 minus predictor 2), with no intercept, is performed to estimate the weighting parameter $\tau$ and its standard error. If the weighting parameter is significantly greater than $0 \cdot 5$, predictor 1 is considered to be significantly superior to predictor 2 ; this test is equivalent to a test of equality of the mean squared prediction errors.

The percent variance explained by each index as well as the relative additional variance was calculated. The latter was derived by calculating the additional variance explained by each index over a model controlling for over 65 , over 75 , and practice. This additional variance was expressed as a proportion relative to the additional variance explained by the basic Jarman index over the model with age over 65 , over 75 , and practice.

\section{Results}

Age was the strongest single predictor of workload and there was a $\mathrm{J}$ shaped relationship. Mean workload score (weighted sum of illness consultations during the year) by age group were: $0-4$ years, $4 \cdot 2(95 \%$ CI $4 \cdot 1-4 \cdot 5)$; 5-64 years, $3 \cdot 2$ (3.2-3.3); 65-74 years, $5.9(5 \cdot 7-6.0)$; $75+$ years, 9.5 (9.4-9.7). Table III shows the $\beta$ coefficients for univariate predictions of workload by each variable, controlling for practice, age over 65 , and age over 75. All variables except geographical mobility were significantly associated with workload; for overcrowding there was an inverse relationship. The multivariate analyses resulted in the coefficients for most variables being slightly reduced except for the "age under 5" variable, where the coefficient was increased (data not shown). Repeat analyses using a weighting score of 3 rather than 2.5 for non-surgery consultations yielded similar results, but the coefficients for car ownership and lone parent were slightly increased.

Table IV compares the weights given to each variable in the Jarman index by the multivariate analysis with the weights used by Jarman which were based on the opinions of general practitioners. The smallest positively associated variable (ethnic origin) was taken as the baseline. The ranking of variables in the multivariate analysis was similar to that derived from the Jarman index but the multivariate analysis assigned more weight to the effect of age under five years.

The derived index contained eight variables: car ownership, age under five years, unemployment, housing tenure, social class IV or V, overcrowding, lone pensioner, and ethnic minority. Table $\mathrm{V}$ shows the percent variance explained by each index and the proportion of variance explained by the Jarman "score" index, Townsend index, and Carstairs index relative to the basic Jarman index. Compared with the basic Jarman index, the Townsend, Carstairs, and derived indices were better predictors and the Jarman score index was worse. When the "age under five years" variable was included in the analysis with the Townsend and Carstairs indices, both these models predicted better than the Jarman index $(p<0.001)$. 


\section{Discussion}

Although the Jarman index was intended to identify practices with greater workload it has not been validated directly against consultation rates except in one study based on self reported consultations in a two week period. ${ }^{8}$ Jarman argued that to validate the score against general practice consultation rates would be inappropriate, since hospital services in deprived areas may compensate for inadequate primary health care so that consultation rates for each practice may not reflect "potential workload". ${ }^{3}$ This argument is valid when consultation rates are compared between areas or practices. However within a practice each individual has the same potential access to available services and the effects of social factors upon workload can be examined by comparing the consultation rates of individuals. Although dealing with consultations takes up two thirds of practitioners' time, ${ }^{19}$ reliance on the consultation rate as an indicator of workload has limitations since workload is also affected by the complexity of the consultations. It is not possible to examine this in the national morbidity study dataset.

There are difficulties in extrapolating from associations at individual level to associations at area level. There may be a relationship between poor areas and health independent of the attributes of individuals in that area. ${ }^{22} 23$ Analysis based on comparison between practices would not help this issue for the reasons discussed above. This problem is common to both our method and that used by Jarman in constructing his index. Jarman asked general practitioners to weight each of the listed attributes "according to the degree to which it increases workload or contributes to the pressure of work when it is present": this is likely to have been interpreted by respondents as a comparison between individuals in the same practice. The weightings were then extrapolated to produce an area based score.

Only a small additional proportion of the variation in consultation rates between individuals is explained by census variables, when age is taken into account. There are many reasons for large variations between practices in mean consultation rates which are unrelated to social deprivation: for example, some doctors may encourage patients to consult more frequently, and the availability of hospital services differs between practices. The effect of these factors on workload is interesting but irrelevant to the assessment of potential workload associated with deprivation. We consider the practice effects in our models to relate to supply factors rather than to demand or "potential workload". The proportion of variance of potential workload (ie, ignoring practice effects) explained by social factors will be far greater at an area level than at an individual level. This is because when the data are aggregated, individual differences in consultation rates will tend to average out while systematic effects of social factors will not. Similarly, the differences between indices in proportion of variance explained are likely to be substantial at an area level even though they are small at an individual level.

The national morbidity study is the largest dataset available to examine the possible relationship between attributes of individuals and general practice workload. Although the age and sex structure of the practice populations is similar to that of England and Wales, the practices are not representative of all practices in the country. ${ }^{18}$ Practitioners in this highly motivated sample may give special attention to their socially deprived patients, biasing the estimates. Unless they favoured certain categories of deprived patients more than others, this would not alter the relative weightings of the variables on which our analyses depend.

Predictions of workload based on the Carstairs and Townsend indices were better than predictions based on the Jarman index. Although the differences were relatively small, this is likely to be far more important at an area level. This is surprising, as the Jarman index was devised specifically to predict general practice workload, whereas the Townsend and Carstairs indices were intended to measure social deprivation generally; because of this difference, the "age under five years" variable, which is not an indicator of social deprivation but a predictor of workload, was not included in the Townsend and Carstairs indices. The inclusion of this variable in a census based score, designed to compensate practitioners, is less rational than directly weighting the capitation fee for this group, as is already done for the elderly. ${ }^{6}$ When age under five years is controlled for, the superiority of the Carstairs and Townsend indices over the Jarman index increases further.

Overcrowding, which is included in all three deprivation scores, was inversely associated with general practice workload. This inverse relationship arises because overcrowding is less common among older age groups which generate greater workload. After controlling fully for age in a regression model, there was a weak positive relationship between overcrowding and workload. The Jarman index includes geographical mobility, which was not associated with increased rates of consultation for illness. Among patients who were geographically mobile, the unemployed were overrepresented, but so were skilled and non-manual workers. This heterogeneity may account for the lack of association between geographical mobility and workload. Jarman has also recently commented that this variable is unrelated to levels of mortality and morbidity. ${ }^{15}$ Our analyses emphasise car ownership and housing tenure, not included in the Jarman index, as among the strongest census based predictors of workload in general practice. Both variables were identified in an alternative score suggested by Scott-Samuel using chronic sickness as the outcome measure. ${ }^{24}$ The list of 13 social factors originally identified by the Acheson Committee included "difficulties visiting" and "poor housing" but these were subsequntly dropped from the Jarman index. Lack of access to a car is likely to increase the need for home visits and is also a powerful predictor of mortality. 25

Social meaning of variables such as car ownership and housing tenure may change over time. Therefore their validity as indicators of socioeconomic status may need reassessment. Unemployment has recently been suggested as a more stable alternative ${ }^{26}$ but in our analysis was not as powerful a predictor of general practice workload as car ownership. 
In conclusion, the Jarman index is weaker than the simpler indices of Townsend and Carstairs in predicting general practice workload because it fails to include car ownership or housing tenure. The validity of overcrowding and geographical mobility as indicators of greater workload is not empirically supported. The weightings used in the Jarman index underestimate the relative importance of children aged under five years in generating work. A more rational remuneration system for general practitioners would include a direct weighting of the capitation fee for children aged under five years. A score similar to the Townsend index would be most appropriate to identify aggregations of social deprivation which increase workload. It has recently been suggested that the choice of deprivation score for remunerating general practitioners is unimportant, as all three indices are highly intercorrelated. ${ }^{27}$ However a high correlation coefficient between two variables does not mean that both measure the same thing. ${ }^{28}$ Areas identified as being most deprived also differ depending which measure is used. ${ }^{1729}$ Using the Townsend index instead of the Jarman index would redistribute resources from London to deprived areas in other parts of the country. ${ }^{17}$

We are grateful to $\mathrm{Mr}$ John Birch and Dr Anna McCormick for providing the data and for helpful comments. The Third National Morbidity Survey was a joint study by the Royal College of General Practitioners, the Office of Population Censuses and Surveys and the Department of Health. Y B-S is a Wellcome Fellow in Clinical Epidemiology.

1 Department of Health and Social Security/General Medical Services Committee Working Party on Underdoctored Areas. Report. London: DHSS, 1980.

2 London Health Planning Consortium Primary Health Care Study Group. Primary health care in inner London. London: DHSS, 1981 .

3 Jarman B. Identification of underprivileged areas. BMF 1983; 286: 1705-9.

1983; 286: $1705-9$. Jarman B. Underprivileged areas: validation
distribution of scores. BMF 1984; 289: 1587-92.

5 Charlton JR, Lakhani $A$. Is the Jarman underpriviliged area 5 Charlton JR, Lakhani A. Is the Jarman
score valid? $B M \mathcal{F}$ 1985; 290: 1714-6.
6 Carstairs V, Morris R. Deprivation and health. $B M F$ 1989; 299: 1462.

299. 1462. $G$ Social deprivation and rates of treated mental disorders: developing statistical models to predict mental disorders: developing statistical models to predict psychiat

8 Curtis SE. Use of survey data and small area statistics to assess the link between individual morbidity and neighbourhood deprivation. $\mathcal{F}$ Epidemiol Community Health $1990 ; 44: 62-8$.

9 Delamothe T. Deprived area payments. BMf 1990; 300 1609-10.

10 Davey Smith G. Second thoughts on the Jarman index. BMF 1991; 302: 359-60.

11 Carr-Hill $R$, Sheldon T. Designing a deprivation payment for general practitioners: the UPA $(8)$ wonderland. $B M \mathcal{J}$ 1991; 302: 393-6.

12 Talbot RJ. Underprivileged areas and health care planning implications of use of Jarman indicators of urban deprivation. BMF 1991; 302: 383-6.

13 Townsend P. Deprivation. I Soc Policy 1987; 16: 125-46.

14 Carstairs V, Morris R. Deprivation and mortality: an alternative to social class. Community Med 1989; 11: 210-19.

15 Jarman B. Social deprivation and health service funding London: Imperial College of Science, Technology and Medicine, 1990;

16 Mays N, Chinn S. Relation between all cause standardised mortality ratios and two indices of deprivation at regional and district level in England. $f$ Epidemiol Community Health 1989; 43: 191-9.

17 Hutchinson A, Foy C, Sandhu B. Comparison of two scores for allocating resources to doctors in deprived areas. $B M$ 1989; 299: 1142-4.

18 Royal College of General Practitioners, OPCS, DHSS Morbidity statistics from general practice: third national study. London: HMSO, 1986.

19 study. London: HMSO, 1986. 292-7.

20 OPCS. Classification of occupations. London: HMSO, 1980.

21 Pocock SJ, Ashby D, Smith MA. Lead exposure and children's intellectual performance. Int f Epidemiol 1987; 16: $57-67$.

22 Haan M, Kaplan GA, Camacho T. Poverty and health Prospective evidence from the Alameda County Study. $\mathrm{Am}$ f Epidemiol 1987; 125: 989-98.

23 Humphreys $\mathrm{K}$, Carr-Hill. Area variations in health outcomes: artefact or ecology. Int $\mathcal{f}$ Epidemiol 1991; 20: $251-8$.

24 Scott-Samuel A. Need for primary health care: an objective indicator. $B M F$ 1984; 288: 457-8.

25 Goldblatt P. Mortality and alternative social classifications. Goldblatt P. Mortality and alternative social classifications. social organisation. London: HMSO, 1990: 164-90.

26 Campbell DA, Radford JMC, Burton P. Unemploymen rates: an alternative to the Jarman index? $B M \mathcal{F} 1991 ; 303$ $750-5$

27 Jarman B, Townsend P, Carstairs V. Deprivation indices BMF 1991; 303: 523 .

28 Bland MJ, Altman DG. Statistical methods for assessing agreement between two methods of clinical measurement. agreement between two 1986 ; i: $307-10$.

29 Radford J, Campbell D. Deprivation indices. BMF 1991 303: 857 . 